\title{
ANATOMÍA DEL CLIENTELISMO POLÍTTCO EN LA ESPAÑA IIBERAL DECIMONÓNICA: UNA REALIDAD ESTRUCTURAL
}

\author{
por \\ XOSÉ R. VEIGA ALONSO \\ Universidad de Santiago de Compostela.
}

RESUMEN: El clientelismo politico aparece en el contexto definido por la España liberal decimonónica como una realidad estructural que domina el conjunto de la actividad politica. El presente articulo parte de la consideración del caciquismo como un fenómeno complejo internamente definido a partir de factores politicoinstitucionales, socioeconómicos y familiares, que tiene como punto nodal la práctica clientelar del favor. Profundamente arraigado en el tejido social, el estudio interno de las clientelas permite señalar las características básicas de los participantes y beneficiarios del entramado caciquil, aportando asi un mejor conocimiento de sus causas y una vía de estudio que ayude a explicar los porqués de su longevidad.

Palabras Clave: España. Siglo XIX. Política. Clientelismo político. Caciquismo.

ABSTRACT: Political clientelism is a structural reality dominatting the whole of political activity in nineteenth-century Spain. This article takes at its starting point a view of utaciquismo" as a complex phenomenon defined by political, economic and family factors twhose focal point is the practice of clientage. The internal study of clienteles allows us to know the basic characteristics of the participants and beneficiaries of the web of caciquismo, bringing a better understanding of its causes and an avenue of inquiry which belps to explain the reasons for its longevity.

KEY wordS: Spanish nineteenth century. Political history, Political clientelism. *Caciquismo*.

\section{INTRODUCCIÓN}

Reflexionar sobre el fenómeno del clientelismo político supone abordar un tema de permanente actualidad que en los últimos años viene ocupando un espacio cada vez mayor en el estudio histórico de la etapa contemporánea ${ }^{1}$. Sin

1 Por ejemplo, RoBles EgEA, A. (comp.), Politica en penumbra. Paironarga y clientelismo politicos en la España contemporánea, Madrid, Siglo XXI, 1996; AlvarAdo, J. (coord.), Poder, economía, clien- 
duda, la existencia de prácticas oscuras en las democracias actuales, la evidencia de políticas basadas en el favoritismo y la corrupción administrativa y la constatación de la vitalidad del llamado clientelismo de partido ${ }^{2}$, son circunstancias del hoy que ayudan a definir las causas de este interés por rastrear en el pasado antecedentes de actitudes visibles aún en la sociedad actual, pero más allá de este presentismo y como explicación básica de las investigaciones, se sitúa la evidencia histórica del clientelismo como realidad estructural presente todo a lo largo de la historia política española del siglo XIX. Desde este punto de partida, la práctica clientelar no puede entenderse como una simple derivación o variante del sistema político ni como una consecuencia más o menos inesperada de su funcionamiento, sino como la clave de bóveda que otorga sentido a la praxis político-electoral y que acaba por definir a la totalidad de las interacciones que se dan entre los actores que la protagonizan.

Pero antes de seguir adelante con la argumentación, me permito hacer una llamada de atención terminológica y metodológica sobre la necesidad de llegar a un acuerdo entre los estudiosos en cuanto a la realidad que esconden términos como clientelismo, caciquismo, patronazgo, intermediación... y a los contenidos de las situaciones que definen, por cuanto con demasiada frecuencia se utilizan indistintamente para referirnos a acontecimientos, actuaciones y relaciones muy diferentes entre si, con significados muy diversos y con implicaciones igualmente muy variadas ${ }^{3}$. Asi, el abuso lingüístico que supone utilizar expresiones como "caciquismo» o "prácticas caciquiles» a la hora de señalar desde el contexto general en que se mueve la política del XIX hasta las conexiones que se establecen entre propietarios y colonos, pasando por las interrelaciones entre centro y periferia (la dialéctica poder central $v$ s. poder local), las formas de engarce-subordinación entre patronos y clientes, la intervención

telismo, Madrid, Marcial Pons, 1997; Fernández Prieto, L., et al (coords.), Poder local, elites e cambio social na Galicia non urbana (1874-1936), Sanciago de Compostela, Parlamento de Galicia-Universidade, 1997. Una perspectiva internacional, en BriquEr, J-L (a cura di), « Clientelismi): Quaderni storici, 97 (1998) 3-142.

2 Cazorla Pérez, J., «El clientelismo de partido en la España de hoy: una disfunción de la democraciay: Revista de Estudios Politicos, 87 (1995) 35-51; Monitesino GonzÁl.cZ, A. « La comunidad imaginada: «etnicidad), «sociedad tradicional» y actual invención de la tradición en Cantabrias, en Id. (ed.), Estudios sobre la sociedad tradicional cántabra. Continuidades, cambios y procesos adaptativos, Santander, Universidad-Asamblea Regional de Cantabria, 1995, págs. 42-48; Ronki. GUEZ, M. A., «Deputacións e poder: os señores do voto": Tempos Noyos, 6 (1997) 12-22. Para el caso (paradigmático) de la Italia posterior a la II Guerra Mundial: CAZzOLA, F., Della corruzione: fisiologia e patologia di un sistema politico, Bologna, il Mulino, 1988; MArino CAFERRA, V., I/ sistema della corruzione: le ragioni, $i$ sogpetti, $i$ luoghi, Roma, Laterza, 1992; GRIBAUd, G. \& MusEILA, L., « Il processo alla clientela. Il caso di Napoli nelle inchieste giudiziarie degli anni Novantav: Quaderni storici, 97 (1998) 115-142; DEl LA PorIA, D., Lo scambio occulto, Bologna, il Mulino, 1992.

3 Fernández Prifto, L et al, "Introducción: poder local e cambio social na Galicia contemporánea. Balances e propostas», en Id. (coords.), cit., pág. 18; Monzno Luzón, J., " Teoria del clientelismo y estudio de la politica caciguily: Revista de Estudios Politicos, 89 (1995) 193; BRsQUET, J-L., "Premessa»: Quaderni storict, 97 (1998) 3.

IILpania, L.IX/2, núm 202 (1999) 637-661 
electoral del ejecutivo o la manipulación municipal del reparto de consumos (por poner sólo un puñado de ejemplos), es evidente, por cuanto en un único término estamos incluyendo multitud de situaciones que, aunque relacionadas entre sí, no representan hechos históricos equiparables, con lo que la expresión empleada pierde capacidad explicativa y analítica al quedar situada en una indefinición totalizante de escasa utilidad práctica. No se trata de elegir entre varias alternativas ${ }^{4}$, sino más simplemente de llamar a cada cosa por su nombre, de diferenciar con claridad lo que son prácticas diferentes y de entendernos a partir de una nomenclatura común y consensuada.

De modo un tanto esquemático y reduccionista, la historiografia ha ordenado los estudios sobre el clientelismo-caciquismo atendiendo a una doble orientación: de un lado, se sitúan los análises que conceden la primacía a los componentes políticos del fenómeno, resaltando la capacidad gubernamental para influir en las consultas electorales empleando la vía jerárquica de la administración y situando en el centro del sistema el punto nodal del entramado caciquil; del otro, los estudios que señalan la trascendencia que la estructura económica dominante tiene a la hora de definir y explicar los comportamientos clientelares, que por lo general conceden una mayor importancia a la presentación de los espacios de poder periféricos (emblemáticamente representados por los propietarios de medios de producción, se presenten en forma de tierras o de fábricas) ${ }^{5}$. En los últimos años, sin embargo, se ha abandonado esta especie de búsqueda de la determinación en última instancia (política vs. economía) en favor de un enfoque más global que sea capaz de dar cuenta de la variedad de facetas que presenta un tema tan complejo como éste cruzado por multitud de

4 Como parece sugerir J. A. DURÁn cuando establece la superioridad de la denominación "caciquismo» frente a otras como "clientelismo" o «patronazgo" por tener un significado más tico y complejo. Vid., "Poder local y organización social-agraria: nuevo repaso al viejo asunto del caciquismo norteñon, en GARCIA MeriNo, L. V., Los espacios rurales cantábricos y su evolución, Santander, Universidad-Asamblea Regional de Cantabria, 1990, págs. 81-82.

5 Para el primer tipo de estudios, entre otros: VAREJ A ORTEG A, J, Los amigos políticos. Partidos, electiones y caciquismo en la Restauración (1875-1900), Madrid, Alianza, 1977; Id., "Orígenes y desarrollo de la democracia: algunas reflexiones comparativasm: Ayer, 28 (1997) 29-60; Romero Maura, J., "El caciquismo: tentativa de conceptualizacións: Revista de Occidente, 127 (1973) 1544; Tusku, J., Oligarquía y Caciquismo en Andalucia (1890-1923), Batcelona, Planeta, 1976... Para el segundo, también entre otros: Durán, J. A., Historia de caciques, bandos e ideologias en la Galicia no urbana, Madrid, Siglo XXI, 1972; TuÑON DE LARA, M., La España del siglo XIX, Barcelona, Laia, 1968; YANINI, A., El caciquisme, Valencia, Institució “ Alfons el Magnànim»-Diputació Provincial, 1984; Ruiz PÉRez, R. \& R, Propiedad de la tierra y caciquismo: el caso del Dólar en los tiempos de Alfonso XIII, Granada, Diputación-Ayuntamiento del Dólar, 1987; Cruz ArTnCHo, S., Caciques y campesinos. Poder politico, modernización agraria y conflictividad rural en Granada, 1890-1923, Madrid, Ediciones Libertarias-Ayuntamiento de Córdoba, 1994... A estos dos enfoques se han referido Garrido MARTín, A., "Historiografia sobre el caciquismo: balance y perspectivas»: Hispania, 176 (1990) 1.349-1.360 y YANINI, A., «La Restauración monárquica y el caciquismo (Revisión bibliográfica)m: Estudis d'bistòria contemporània del País Valencià, 1 (1979) 295-312. En realidad, la división es rígida en exceso y no refleja el conjunto de matices que aporta cada autor, si bien resulta válida como primera aproximación al tema. 
interrelaciones, y que se roza con la práctica totalidad de las estructuras que conforman el contexto vital del individuo (políticas y económicas, pero también sociales, relacionales, familiares, religiosas...). Evidentemente, no se trata de caer en una argumentación circular que conceda idéntica importancia a todos y cada uno de los determinantes que influyen en la dinámica caciquil, sino de partir de un enfoque plural y abierto, no reduccionista y atento al conjunto de posibles factores incidentes, para en un segundo momento, de acuerdo con las peculiaridades de cada caso y con la información empírica disponible, intentar establecer (de ser posible) una jerarquía que los ordene fijando las interconexiones que los unen. En estrecha relación con este último aspecto, y asimismo como tendencia visible en la historiografía más actual, hay que señalar el cambio de orientación experimentado en la metodología y los fundamentos teóricos de la historia política, que de una preocupación limitada, en el asunto que nos ocupa, fundamentalmente a la faceta electoral, ha pasado ahora a interesarse por historiar no tanto la política (lo que hacen los políticos profesionales o los partidos) como lo político (el conjunto de actuaciones, contextos espaciales, actores sociales y redes relacionales de diverso contenido y naturaleza implicadas e interrelacionadas en la lucha por el poder). Y ésto porque la historia política debe de concebirse como una historia por el acceso al poder, por llegar a administrar los medios de control social que proporciona y los beneficios que de su usufructo se derivan para los grupos que logran hacerse con. él ${ }^{6}$. Un esquema que resulta especialmente válido aplicado al panorama político del siglo XIX español, dominado como estaba por agrupaciones faccionales de carácter fuertemente personalista, escasamente definidas por criterios ideológicos y primordial y principalmente interesadas en lograr un uso privativo y particularista de los espacios de poder institucionales. Entendiendo la telación caciquil como una realidad de poder que va mucho más allá del momento electoral y del estricto ámbito de la política (aunque también participa de él), y privilegiando un enfoque que tome en cuenta los factores sociales (familiares, relacionales, de solidaridad de grupo) y económicos que igualmente

6 Sobre los nuevos rumbos de la historia política: Historia Contemporánea, 9 (1993: monográfico); Carnsa Soto, P., Elites. Prosopografía contemporánea, Valladolid, Universidad, 1994 (en especial los trabajos de Sol $\dot{\lambda}, A$, págs. 25-34 y CArAsı Soto, P., págs. 41-51); Quintrana Garrido, $\mathrm{X}$. R., «O poder dos actores. O tenacemento da listoria política): $A$ Trabe de Ouro, IV (1998) 459-480; PÉcourr, G., «L'histoire politique et la «crise» de l'histoire: un écho au livre de Gérard Noiriels: Bulletin de la Societé d Histoire Moderne et Contemporaine, $3-4$ (1998) 113-116; Rèmono, R., Pour une bistoire politique, Paris, Seuil, 1988. Para el complejo y debatido tema de la politización campesina, PECOUr, G., « La politisation des paysans au XIXème. siècle. Réflexions sur l'histoire politique des campagnes françatses»: Histoire et Sociatés Rurales, 2 (1994) 91-125. La centralidad del concepto poder, en: Weingrod, A., « Patronazgo y poden, en Gej.INER, E. et al, Patronos y Clenter, Madrid, Júcar, 1986, págs. 63-77; Tosens I SAN'TAMnNs, E., "Sobre la qüestió política local a mitjan segle XTX. Aproximació a l'estudi de les relacions entre els poders locals i l'ajuntament al municipi de Sarrì en 1840-1856m: Estudis d'bistòria agrària, 9 (1992) 74; SUAu, J., "Qui mana? Com? Per què? Estudi de les relacions de poder en les collectivitats rurals»: L'avenf, 160 (1992) 35 .

Hiopania, LIX/2, núm. 202 (1999) 637-661 
tienen protagonismo, estaremos en disposición de acercarnos a una explicación integral de la práctica clientelar.

\section{LAS BASES DEL PODER CIIENTEIAR}

La definición primigenia de clientelismo presenta una clara derivación antropológica. Por relación clientelar entendemos aquella que se establece entre dos individuos situados en diferentes niveles de poder (tanto desde un punto de vista político como socioeconómico: conexión jerárquica, vertical y asimétrica) que protagonizan un intercambio mutuamente beneficioso de bienes y servicios de distinta condición. El contacto implica la existencia de un patrón (ubicado en una posición de privilegio y demandante, básicamente, de deferencia y respeto públicos amén de apoyo político general) y de un cliente (no forzosamente un subordinado pero sí álguien dotado de menor capacidad de relación y negociación que su patrón, en busca de ptotección, favores individualizados $y$, en general, un trato de favor) que mantienen un contacto directo y diádico, bis a bis e incluso dotado de ciertos componentes afectivos, si bien tanto éstos como el grado de reciprocidad en la relación pueden vatiar desde un engarce patrón-cliente casi de primus inter pares a otro en que el beneficio mutuo se diluye hasta prácticamente desaparecer, siendo entonces difícil hablar propiamente de clientelismo ${ }^{7}$. Partiendo de esta definición básica, el análisis histórico (como el politológico y el sociológico) lo que hace es complejizarla integrando en el estudio un mayor númeto de componentes y variables (dotarla de historicidad) ${ }^{8}$, de tal modo que sin perder el carácter diádico original se pue-

7 GELLNER, E. et al, cit.; MÁIZ, R., “ Estrategia e institución: el análisis de las dimensiones macro del clientelismon, en Robles EGEA, A. (comp.), cit., págs. 43-67; Id., "Estructura y acción: elementos para un modelo de análisis micropolítico del clientelismon: Revista Internacional de Sociologia, 8-9 (1994) 189-215; Id., «Desconfianza e poder persoal: os mecanismos elementais do clientelismo políticon: $A$ Trabe de Ouro, 31 (1997) 13-31; GonZÁs,EZ ALCANTUD, J. A., El clientelismo politico. Perspectiva socioantropológica, Barcelona, Anthropos, 1997; Id., "Jerarquía versus igualdad. El clientelismo político mediterráneo desde la antropología sociabs, en ROBLES EGEA, A. (comp.), cit., págs. 21-42; Con'rRERAS, J., « Estratificación social y relaciones de podeo, en PRAT, J., Mar'tine'z, U., Contreras, J. \& Moreno, I., (eds.), Antropologia de los pueblos de España, Madrid, Taurus, 1991, págs. 499-519; MÉdard, J-F., « Le rapport de clientèle: du phénomene social à l'analyse politiques: Revtue françatse de science politique, 26 (1976) 103-131; GrazIANO, L. (a cura di), Clientelismo e mutamento politico, Milano, Franco Angeli, 1974; ClapHaM, CH. (ed.), Private Patronage and Public Power. Political Clientelism in the Modern State, London, Frances Pinter, 1982; Bourne, J. M., Patronage and Society in Nineteenth-Century England, London, Edward Atnold, 1986; EisenSTADT, S. N. \& Roniger, L., " Patron-Client Relations as a Model of Structuring Social Exchangen, Comparative Studies in Society and History, 22 (1980) $42-77$ (con abundante bibliografia sobre el tema); Id., Patrons, Chents and Friends: Interpersonal Relations and the Structure of Trust in Society, Cambridge, CUP, 1984; Borssivain, \}., Friends of Friends, Oxford, Basil Blackwell, 1978.

8 ForCADELl Állyarez, C., «De la Revolución democrática a la Restauración: El horizonte de una historia socialy, en MORAles MoYA, A. \& Esteban de VEGA, M. (eds.), La bistoria contemporánea en España, Salamanca, Universidad, 1996, pág. 117.

Hispanta, LIX/2, nủm. 202 (1999) 637-661 
da dar el salto de la conexión singular patrón-cliente a un conjunto integtado por múltiples engarces de este tipo: pasamos entonces a hablar de las pirámides o redes clientelares?. Aquí el esquema jerárquico, vertical y personal patróncliente se mantiene intacto, pero pasa a contemplarse y analizarse integrado dentro de una red social informal (social network) dotada de gran variedad de contactos similares, de tal modo que un único patrón puede mantener vínculos particulares con varios clientes, quienes a su vez se nos aparecen ejerciendo como patronos de sus respectivas microclientelas. El carácter informal de los contactos viene derivado de su no adecuación a criterios jutídico-legales, institucionales o públicos (como pueden ser los establecidos para ejercer la militancia en un partido político, por ejemplo); por el contrario, responden a pautas estrictamente privadas, personales y subjetivas (no formalizadas), lo que dota a estas redes de una gran flexibilidad y de unos límites particularmente difusos que les permiten extenderse por todo el entramado social, atravesando las batreras de clase y generando una estructura faccional y segmental en la que los contactos entre actores situados al mismo nivel quedan subsumidos dentro de la predominante relación jerárquica y vertical. Las implicaciones políticas y sociales de una construcción de este tipo, en cuanto desincentivadora de toda movilización colectiva y de toda estrategia de organización clasista, son evidentes desde el momento que el cliente queda aislado de su propia clase y entra en competencia con sus semejantes por lograr el apoyo del patrón ${ }^{10}$.

De hecho, el estudio empírico demuestra que dentro de las redes clientelares los engarces se realizan siempre siguiendo un sentido vertical, estrictamente jerárquico y atendiendo a una dinámica individual, sin implicar a grupos organizados horizontalmente que transmitan en conjunto sus demandas. Tal esquema favorece el mantenimiento de la autoridad del patrón, que al tratar individualmente con cada cliente y situarse en una posición de poder superior

9 Mázz, R., «Estrategia e institución...», cit.; WELLMAN, B., « Analisis strutturale: un paradigma alternativon, en PISELII, F., (a cura di), Reti. L'analisi di network nelle scienze socialt, Roma, Donzelli, 1995 , págs. $27-49$.

10 MÁrZ, R., "Desconfianza e poder...», cit, pág. 22; THerborn, G., zCámo domina la clase dominante?, Madrid, Siglo XXI, 1979, págs. 229-230; ALAVI, H., Las clases campesinas y las lealtades primordiales, Barcelona, Anagrama, 1976, págs. 89-93; CrUZ ARTACHO, S., «Estructura y conflicto social en el caciquismo clásico. Caciques y campesinos en el mundo rural granadino (18901923)", en Robles EGeA, A., (comp), cit., págs. 197-199; MAYER, A. C., "La importancia de los cuasi-grupos en el estudio de las sociedades complejas", en BanTon, M. (comp), Antropalogía social de las sociedades complejas, Madrid, Alianza, 1990, págs. 108-133; LEWELLEN, T. C., Introducción a la Antropología Politica, Barcelona, Bellaterra, 1985, págs. 111-112. La utilidad de los métodos del network anahysis en el estudio de estas redes clientelares informales es muy elevada. Sobre el tema: PRo RUIz, J., "Las élites de la España liberal: clases y redes en la definición del espacio social (1808-1931)y: Historia Social, 21 (1995) 63; RoDrícuez, J. A., Análisis estructural y de redes, Madrid, CIS, 1995; PISELLI, F., cit.; GrIBAUDI, G., « La metafora della rete. Individuo e contesto sociale): Meridiana, 15 (1992) 91-108; Scotr, J., Social Network Analysis, London, Sage, 1991; Knoke, D., Political Networks: The Structural Perspective, Cambridge, CUP, 1990.

Hilpanta, LIX/2, núm. 202 (1999) 637-661 
goza siempre de una gran ventaja en la negociación ${ }^{11}$. Este componente de singularidad resulta a todas luces fundamental para la continuidad de la política clientelar, pues cualquier agrupación clasista de clientes (objetivamente unidos por problemas y necesidades comunes) supondría la base de una potencial movilización y un peligro evidente para la supervivencia de la red caciquil y para el papel central concedido al patrón. Estaríamos hablando entonces de política de clase y no de una segmental y faccional (o de status) ${ }^{12}$.

El caciquismo-clientelismo como base estructural de la política decimonónica no es una realidad que pueda, en absoluto, circunscribirse al período de la Restauración, ya que se encuentra presente desde los mismos orígenes del Estado liberal español logrando adaptarse con éxito a las circunstancias de un contexto en permanente evolución ${ }^{13}$. En realidad, las prácticas clientelares y el favoritismo se rastrean ya con facilidad todo a lo largo del Antiguo Régimen ${ }^{14}$

11 Es el caso, por ejemplo, de la clientela de que dispone el conde de Pallares en el distrito de Mondoñedo (Lugo) en la década de 1860. El Conde trata siempre de modo individual con cada uno de los integrantes, hasta el punto que en un primer momento sólo él conoce a la totalidad de sus clientes en tanto que éstos ignoran quienes son sus compañeros de red. Al exigir el entramado clientelar sólo relaciones a nivel vertical (de cada cliente con su pattón), Pallares logra integrar entre sus apoyos a notables locales que incluso mantienen una abierta hostilidad entre sí, sin que ésto constituya inconveniente alguno para que todos actúen como agentes político-electorales suyos. Vid., VEIGA Alonso, X R., O conde de Pallares e o seu tempo, 1828-1908. Aproximación ó ativismo das elites na Galicia decimonónica, Lugo, Deputación, 1999, págs. 209-210 (en imprenta). El repaso de los cientos de cartas cruzadas entre Pallares y sus protegidos demuestra sin lugar a ninguna duda que la relación clientelar que mantienen es estrictamente individual y que los favores y gestiones solicitados son siempre de carácter personal. Las peticiones de carácter colectivo carecen numéricamente de relevancia y constituyen una excepción. Pueden consultarse en el Arquivo Histórico Provincial de Lugo, serie Xeral, documentación del conde de Pallares, legajos 1-18 bis (en adelante, AHPL, CP)

12 ANDrEuCCI, F, " La norma e la prassi. Le elezioni irregolari nell Ttalia liberale (18611880)»: Passato e presente, 34 (1995) 63.

13 Artrol, M., Partidos y programas politicos, 1808-1936. I. Los partidos politicos, Madrid, Alianza, 1991 (1977), págs. 119, 269; AguILAR GaviLẢN, E., Vida politica y procesos electorales en la Córdoba isabelina (1834-1868), Córdoba, Publicaciones del Monte de Piedad y Cajas de Ahorro, 1991; PEREZ GARCÍA, J. M., Elecciones y diputados a Cortes en Las Palmas durante el siglo XIX, Las Palmas, Cabildo Insular, 1990; CABALLLRO, M., El Sufragio Censitario. Elecciones generales en Soria durante el reinado de Isabe/ II, Ávila, Junta de Castilla y León, 1994. Para el caso gallego, TABOADA MOURE, P., Las elites y el poder politico. Elecciones pravinciales en Pontevedra (1836-1923), Pontevedra, Deputación, 1987; Barreiro FERnANDEZ, X. R., «Las elecciones de la Unión Liberal (1858) en la provincia de Orense y el tema del caciquismo", en JUANA, J. de \& CASTRO, X. (eds.), 1 xornadas de Historia de Galicia, Ourense, Deputación, 1985, págs. 49-92.

${ }_{14}$ Quintanilla Raso, $\mathrm{M}^{2} \mathrm{C}$., “ Facciones, clientelas y partidos en España en el tránsito de la Edad Media a la Modernidad», en Alvarado, J. (coord.), cit, págs. 15-50; Cristóbal MARTín, A., "Amistad, parentesco y patronazgo: redes vinculares y servidores inquisitoriales en el Tribunal de Logroño (s. XVII)»: Historia Social, 17 (1993) 21-31; PÉrez PICAZo, M T. \& LeMEUNIER, G., «Forme di potere locale nella Spagna moderna e contemporanea: dalle fazioni al cacichismo nel regno di Murcia (secoli XVI-XIX)»; Cheiron, 5 (1986) 105-129; WINDIER, CH., " Mediando relaciones. Redes sociales y cambio político a finales del Antiguo Régimenu: Hispa- 
(la Old Corruption de que hablan los historiadores ingleses), pero las implicaciones que tienen en cada momento son muy diferentes: en la etapa moderna la desigualdad legal y la diferenciación estamental son normas institucionales que convierten al favoritismo, la cooptación, el nepotismo o la venalidad de los oficios en estrategias admisibles por la ley, pero con la ordenación constitucional que traen consigo los movimientos liberales todo cambia por lo que este tipo de prácticas pasan a considerarse, por lo menos desde un punto de vista legal, como no admisibles. El problema que se plantea, evidentemente, es la inadecuación entre lo legaly lo real, de tal modo que las actuaciones basadas en la discriminación, el trato de favor o la manipulación de la ley continúan y se perpetúan (adaptándose) hasta nuestros días. Ésto es lo que lleva a algunos estudiosos a hablar del clientelismo como de una estructura mental fuertemente enraizada en el comportamiento colectivo, como de una mentalidad inserta en la larga duración que, partiendo de la experiencia antiguoregimental dominada por criterios personales de dependencia-subordinación, se prolonga bajo los regimenes liberales de tal forma que, a la hora de canalizat determinadas demandas y ambiciones, se otorga preferencia al contacto privado, particular y oficioso frente a los cauces legalmente establecidos (por otro lado, nada claros y escasamente sistematizados). No obstante, esta mentalidad no aparece y se desarrolla porque sí sino que tiene sus explicaciones materiales: 1) históricamente, y hablo en referencia a la situación propia del A. Régimen, en la experiencia acumulada por generaciones de que las cosas funcionan así, de que sólo acudiendo al contacto adecuado se pueden satisfacer determinadas aspiraciones y, 2) en la práctica del día a día a partir del establecimiento de la ordenación jurídica liberal, las más de las veces letra muerta para la mayoría de la población (que sólo percibe los deberes y casi nunca los derechos) ${ }^{15}$, que toma rápidamente consciencia de su inoperancia práctica y que descubre en los mismos bacedores de la ley a sus ptimeros incumplidores ${ }^{16}$. Desde este punto de vista, el recurso a los modos y maneras caciquiles podría entenderse como una práctica adaptativa de la comunidad (de aquella fracción privilegiada con posibilidad de tecurrir a ella) ante una ley lejana, extraña y hecha a sus espaldas, una ley que sólo permitía conseguir algún beneficio manipulándola por la vía del patrón intermediario. Lo que ocurre es que esta transgresión interesaba y beneficiaba

\footnotetext{
nia, 199 (1998) 575-605; Durand, Y. (dit.), Hommage à Roland Mousnier. Clientèles et fidélités en Europe à lepoque moderne, Paris, PUF, 1981.

15 GIL NovNles, A., "Oligatquía y caciquismo, en perspectiva): Ler bistória, 32 (1997) 153.

16 La retórica anticaciquil está cargada de un cinismo depurado, por cuanto los mismos políticos que declamaban contra este tipo de prácticas eran los primeros en practicarlas y sacar provecho de ellas. Vid., Moreno Luzón, J, «El conde de Romanones y el caciquismo en Castilla (1888-1923)»: Investigaciones Históricas, 16 (1996) 148; Or'rl, A., "Estudio introductorio», en COSTA, J., Oligarquia y caciquismo como La forma actual de gobierno en España: urgencia y modo de cambiarla, v. I, Madrid, Ediciones de la Revista del Trabajo, 1975, pág. CXXVIII: « (...) protestar, protestar como inmaculadas vestales de la democracia contra la corrupción politica nacional en la que muchos de ellos participaban como agentes principales o conscientes encubridores».
}

Hipqunia, LIX/2, núm 202 (1999) 637-661 
más a los caciques que a sus clientes (y mucho más a éstos que a los excluidos de las clientelas, como luego veremos), pues contribuia a perpetuar un sistema intrínsecamente favorable para los primeros y reproductor de las desigualdades existentes. Por lo tanto, esa mentalidad clientelar de la que hablábamos es el fruto de una muy real y amplia experiencia histórica y no de un particular $\mathrm{e}$ indefinido ethos mediterráneo. Lo que nos lleva directamente a una segunda precisión referida a la geografía caciquil-clientelar: lejos de representar una anomalia propia y exclusiva de la Península Ibérica (o de los países ribereños del Mediterráneo), aparece extendida de modo casi universal con la temporalidad y las características propias de cada caso por lo que en absoluto cabe hablar de excepcionalidad ibérica ${ }^{17}$. Libres ya de esta pesada carga, centraremos ahora el discurso en la cuestión que encabeza el epigrafe intentando la presentación y definición de las bases del poder clientelar.

$\mathrm{E}$ lanálisis parte de la consideración del caciquismo-clientelismo como un fenómeno complejo y no reducible a una explicación de carácter unívoco. Del mismo modo, no lo contempla como una realidad aislada que se pueda estudiar sin tener en cuenta el contexto general de referencia (político-legal, económico, social e ideológico-cultural) sino que, muy al contrario, lo entiende inmerso en él y participando de las interrelaciones que entre todas estas esferas de actuación se establecen. Por último, y como tercer apriorismo a tener en cuenta, partimos de una caracterización faccional del espacio político del momento definido por una actividad pública organizada por la vía de los bandos y facciones (que nuclean y compartimentan internamente unos desestructurados partidos de notables) ${ }^{18}$, todos ellos guiados por un objetivo común: la

17 VARELA ORTEGA, J., "Sobre la naturaleza del sistema político de la Restauración», en Gortízar, G. (ed.), Nación y Estado en la España Liberal, Madrid, Noesis, 1994, pág. 187; Id., " Origenes y desarrollo..,», cit.; TuSElL, J., «El sufragio universal en España (1891-1936): un balance histotiográficon: Ayer, 3 (1991) 22; LENCLuD, G., "Avant-propos): Terrain, 21 (1993) 5-8; Almeida, P. T. de, Eleigoes e caciquismo no Portugal oitocentista (1868-1890), Lisboa, DireL, 1991, págs. 22-27; CLAPHiAM, CH. (ed.), cit.; LiTTLE, W. \& POSADA-CARBÓ, E. (eds.), Polítical Corrupcion in Europe and Latin America, London, MacMillan Press, 1996; MANN, M., Las fuentes del poder social, II, Madrid, Alianza, 1997, págs. 592-604.

18 BARRED FONTES, J. Ma , Caciques y electores. Ciudad Real durante la Restauración. 1873-1923, Ciudad Real, Instituto de Estudios Manchegos, 1986, págs. 271-272; PEÑA Guevrero, Ma A., El sistema caciguil en la provincia de Huelva: clase palitica y partidos (1898-1923), Córdoba, Ayuntamiento-Ediciones de la Posada, 1993, págs. 111, 145; YANINI, A., El caciquisme, cit., pág. 27; CAs. TELLS, L, Modernización y dinámica politica en la sociedad guipuzcoana de la Restauración, 1876-1915, Madrid, Siglo XXI-Universidad del País Vasco, 1987, págs. 308-310; Real CUEsTA, I., Partidos, elecciones y bloques de poder en el País Vasto, 1876-1923, Bilbao, Universidad de Deusto, 1991, págs. 67-68; CRUZ ARTACHO, S., Caciques y campesinos..., cit., págs. 37-39; Id., "Estructura y conflicto...», cit., págs. 197-199. A nivel europeo, y hasta finales del XIX (según otros autores hasta la I Guerra Mundial), la situación no era muy diferente, sólo con las excepciones parciales de Inglaterra y Francia: RÉMOND, R., "Les élections», en Id., Pour une bistoire politique, Paris, Seuil, 1988, págs. 54-57; Tlengariunha, J. M., Estudos de História Contemporânea de Portugal, Lisboa, Ed. Caminho, 1983, pág. 88; Pomineni, P., Introduzione alla storia dei partiti politici, Bologna, il Mulino, 1990; Id. (a cura di), La trasformazione politica nell Europa liberale, 1870-1890, Bologna, il Mulino,

Hìpania, LIX/2, núm 202 (1999) 637-661 
consecución y el aprovechamiento particular del poder institucional. En consecuencia, y tal como corresponde a la política faccional, es la búsqueda y el usufructo clientelar de ese poder la que confiere identidad a las agrupaciones personalistas que actúan en la arena pública ${ }^{19}$, con lo que la componente ideológica ( $y$ sus derivaciones aparejadas: consecución de beneficios colectivos, movilización y encuadramiento de la población, programas de gobierno públicos y definidos...) apenas si tiene importancia a la hora de identificar las bases en que se apoya esta particular forma de bacer política ${ }^{20}$.

La práctica de una actuación basada en criterios ideológicos exige, entre otras condiciones, la existencia de una nítida separación entre la esfera de lo público (político) y la de lo privado de tal modo que no se produzcan interferencias entre los dos ámbitos. La política debe de contar con un espacio propio y autónomo (evidentemente en conexión con la sociedad pero no determinada por sus relaciones) en el que desarrollarse y en el que poder moverse sin depender de condicionantes privados, situación que en absoluto se produce en la España del XIX donde, precisamente, la privatización y la ausencia de autonomía de la política (muy conectada con el conjunto de las relaciones sociales) son las

1986; MatTEuCCl, N. \& PombEN1, P. (a cura di), L'organizzazione della politica. Cultura, istituzioni, partiti nell: Europa liberale, Bologna, il Mulino, 1988 (en especial, los trabajos de FEucHTWANGER, E. J. « Lo sviluppo del sistema partitico inglese alla fine del XIX secolo: la supremazia ininterota del parlamento», págs. 281-289 y POMsENI, P., «Teoria dei partiti ed esperienza costituzionale nell"Europa liberale», págs. 291-311); ROMANELLI, R., "Le regole del gioco. Note sull'impianto del sistema elettorale in Italia (1848-1895)»: Quaderni storici, 69 (1988) 696, 700; M^NN, M, cit., págs. 36, 884.

19 Sartori, G., Partidos y sistemas de partidos, I, Madrid, Alianza, 1980, págs. 54-55, 105-106; GonZÁlez AlCANTUD, J. A., cit., págs. 56-57; LeWELlen, T. C., cit., págs. 111-112.

20 Garrido Martín, A., Cantabria, 1902-1923: elecciones y partidos politicos, Santander, Universidad-Asamblea Regional de Cantabria, 1990, págs. 41-42; CASTRILLEjo Ibáñez, F. \& FERNÁNDEZ SANCHA, A., "Diputados y senadores burgaleses de la Restauración: análisis y valoración de una élite política en una sociedad con bajo nivel de colisións: Investigaciones Históricas, 16 (1996) 121-122; RuIz PÉrEz, R. \& R., cit., pág. 208; CARASA SOTO, P., «Élites castellanas de la Restauración: del bloque de poder al microanálisis»: Historia Contemporánea, 13-14 (1996) 166, 192-193; Id. et al, « Historia local y prosopografia aplicadas al análisis de una estructura de poder. Diputados zamoranos a Cortes entre 1876-1910n, en VV.AA., Fuentes y métodos de la bistoria local, Zamora, Confederación española de centros de estudios locales, 1991, págs. 478, 484; Id. (dir.), Élites castellanas de la Restauración. Una aproximación al poder politico en Castilla, II, Salamanca, Junta de Castilla y León, 1997, pág. 34; CaBALlero, M. et al, « Las elites politicas en la provincia de Soria: los diputados a Cortes en la Restauración (1875-1923)»: Investigaciones Históricas, 15 (1995) 48, 52-53; SIERRA, M², "L a politica del pacto» El sistema de la Restauración a trasés del partido conservador sevillano (1874-1923), Sevilla, Diputación, 1996, págs. 129, 137; ROMANO, R. \& VIVAN. $\mathrm{Tl}, \mathrm{C}$. (cootds.), Storia d Ttalia, IV. DallUnità a oggi, Torino, Einaudi, 1976, págs. 1.735-1.737; BRlQUET, J-L., "Potere dei notabili e legittimazione. Clientelismo e politica in Corsica durante la Terza Repubblica (1870-1940)»: Quaderni storici, 94 (1997) 145-146; CAMmarano, F., "Logiche comunitarie e associazionismo politico nella Gran Bretagna tardovittoriana: procedure elettorali e « «corruzionem: Quaderni storici, 69 (1988) 844, 849; LENCLUD, G., "De bas en haut, de haut en bas. Le système des clans en Corsen: Études rurales, 101-102 (1986) 157.

Hispania, LIX/2, núm 202 (1999) 637-661 
notas dominantes ${ }^{21}$. En consecuencia, es en el conjunto de estas relaciones y en su impúdico engarce con el contexto político donde debemos de situar los condicionantes reales del voto, las razones últimas explicativas de las fidelidades públicas.

Como primer elemento a considerar en la construcción del apoyo políticoelectoral, y con un marcado carácter general por estructurar el conjunto de las relaciones patrón-cliente, está la práctica del favor, componente básico y central de toda política clientelar y presente de un modo constante y evidente en la dinámica pública del Estado español decimonónico ${ }^{22}$. La interiorización en el subconsciente colectivo de esta fórmula por parte de una sociedad históricamente acostumbrada a una resolución particular y privada (estrictamente personal) de sus reclamaciones, es absoluta, a lo que contribuyen decisivamente las amplias lagunas legales existentes en materias tan esenciales como la contratación de funcionarios públicos, lo que deja un enotme margen de maniobra a las estrategias del favoritismo administrativo ${ }^{23}$. De este modo, la dinámica favor a cambio de voto (en general, de apoyo político entendido en sentido amplio, lo que incluye desde la concesión del sufragio hasta la formación de partidas de la porra con que amedrentar a los rivales) aparece con gruesos trazos como una de las líneas de contacto entre el patrón y los inte-

21 Garrido Martin, A., Favor e indiferencia. Caciquismo y vida politica en Cantabria (19021923), Santander, Universidad de Cantabria-Asamblea Regional de Cantabria, 1998, pág. 194. Para Italia destacan lo mismo SAPELL, G., « Lo Stato italiano como (dimprenditore politicon: Storia contemporanea, 2 (1990) 261 y CAZZOLA, F., « Poderes locais e grupos dirixentes na Italia tutal entre os séculos XIX e XX", en Fernández Prieto, L., et al (coords.), cit., pág. 199.

22 Tusell Gómez, X., « El funcionamiento del sistema caciquil en Andalucía (18901931)", en PAYNE, S. G. (ed.), Politica y sociedad en la España del sigho XX, Madrid, Akal, 1978, págs. 27-28; VILlACorTa Baños, F., Profesionales y butbcratas. Estado y poder corporativo en la España del siglo $X X, 1890-1923$, Madrid, Siglo XXI, 1989, pág. 34; SiERrn ALONSO, $\mathrm{M}^{2}$, "Clientes, caciques y notables políticos: mecanismos de control electoral en la Sevilla de la Restauracióny: Trocadero, 5 (1993) 403; Moreno Luzón, J., « Romanones: Conquistador de clientelas, gran señon: Historia Contemporánea, 13-14 (1996) 286-287; Id., «El conde de...», cit., pág. 151; HidALGo MARín, I. S., «La familia Gamazo: elite castellana en la Restauración (1876-1923)»: Investigaciones Históricas, 15 (1995) 112; ZuRITA, R., « La natura del potere politico nella Spagna della Restaurazione (1875-1902): un bilancio storiografico»; Quaderni storici, 87 (1995) 823; AGUIRRE, M E., « El sistema caciquil en España (1876-1923)»: Atbor, 430 (1981) 79.

23 Me refieto en concreto a este colectivo de funcionazios y empleados públicos por ser la Administración el espacio más afectado (y apetecido) por las prácticas del favor. Así lo demuestra, por ejemplo, el estudio realizado sobre una muestra de 486 solicitudes de recomendación recibidas por el conde de Pallares (diputado conservador lucense) a lo largo de la segunda mitad del s. XIX, del cual se desprende que nada menos que el $84,8 \%$ de las peticiones guardan relación directa con el ámbito administrativo. Vid., VEIGA ALONSO, X. R., « Los marcos sociales del clientelismo políticom: Historia Social (en prensa). Una aproximación a la legislación decimonónica tespecto de la contratación de funcionarios, en MORLLO-VELARDE PÉREZ, J. I., “A selección dos funcionarios públicos de 1808 a 1964», en BARreIRO FERNÁNDEZ, X. R. \& GONZÁlEZ Mariñas, P. (dirs.), III Simposio de Historia da Administración Pública, Santiago de Compostela, EGAP, 1997, págs. 79-98. 
grantes de su red clientelar ${ }^{24}$. No obstante, y como más adelante veremos al estudiar internamente las clientelas, el mecanismo del favor esconde en su seno toda una serie de gradaciones en función de la caracterización del cliente, de su posición de poder relativa respecto del patrón-broker y de la cantidad de apoyo político que aquél esté en disposición de ofrecerle.

Junto a esta práctica del favor, y como un segundo sumando explicativo de las fidelidades clientelares, hay que situar la instrumentalización política de las relaciones familiares y de parentesco (entendidas en sentido muy amplio). La familia, por su carácter de red social aglutinante y de marco primigenio de referencia, actúa en este contexto como el apoyo básico ( $y$ en ocasiones central) en el que se fundamenta la actividad política de uno o varios de sus miembros: ella transmite el prestigio acumulado por los antepasados (en forma de berencia inmaterial) que legitima en el hoy el activismo público y lo convierte en la prolongación natural de un protagonismo asentado en el pasado; ella da cobijo y protección, además de proporcionar contactos, a los vástagos dispuestos a iniciar el camino que los lleve a las Cortes; ella aporta actores dispuestos a ejercer como peones locales del político de la familia (los inevitables y precisos agentes electorales con presencia diaria en el distrito y que recurriendo a prácticas endogámicas controlan, por ejemplo, los ayuntamientos); ella permite perpetuar en el tiempo el control político-electoral con la transmisión del acta de padres a hijos; ella produce los/as descendientes que convenientemente desposados/as permiten acrecentar las bases del poder... ${ }^{25}$. La saga lucense de los Vázquez de Parga constituye una ejemplificación empírica casi perfecta de todo lo expuesto: D. Antonio Vázquez de Parga, subdelegado de Rentas Reales en Lugo, resulta elegido diputado para las cortes gaditanas de 1811; su hijo Manuel (conde de Pa-

24 Hasta tal punto es assi que en las cartas electorales que el conde de Pallares dirige a los electores del distrito lucense de Mondoñedo en 1863, inmediatamente después de solicitar su voto y relaciones se ofrece como gestor para todo aquello que el potencial cliente necesite. Ver, AHPL, CP, legs. 9 y 18 bis. De hecho, el que en ese momento ejercía como diputado por Mondoñedo (Gumersindo Iglesias Barcones) era casi unánimemente rechazado por sus antiguos votantes porque luego de haberlo apoyado en las elecciones de $1858 \mathrm{nada}$ (ningún favor) había hecho por ellos. Ver, carta de F. Lago a Pallares (17-II-1860); ibid., leg. 9.

25 McDonogh, G. W., Las buenas familias de Barcelona. Historia social de poder en la era industrial, Barcelona, Omega, 1989; CRUz ArTACHO, S., Caciguer y campesinos..., cit., pág. 184; MARTiNEZ MARTIN, M. et al, "La propiedad de la tierra como fuente de poder local. Santa Fe entre el voto censitario y el sufragio universab: Trocadero, 5 (1993) 230-235; CARASA, P. (dir.), "Poder político, poder económico y parlamentarismo en Castilla durante la Restauracióny: Revista de Estudios Politicos, 93 (1996) 147-148; CARASA SoTO, P. \& DiEz CANO, L-S., \& La elite parlamentaria salmantina de la Restauracióny: Studia bistórica. Historia contemporónea, 13-14 (1995-96) 45; SEGALEN, M., Antropología bistórica de la familia, Madrid, Taurus, 1992, págs. 69-74; BoDeman, Y. M., " Familismo y patronazgo como sistemas de poder local en Cerdeñas: Papers, 11 (1979) 17-43; Bus. SETT1, F., «Ceti dirigenti a Nami nel XIX secolo»: Proposte e ricerche, 37 (1996) 165, 169; MUSELLA, L. \& SALVEMIN1, B. (a cura di), Storia dTtalia. Le regioni dall Unità a oggi. La Pugkia, Torino, Einaudi, 1989, pág. 330; MoLJICA, L., « Terra, parentela, élites locali: Carlentini nel primo Ottocento»: Materiali IMES. 3. Potere bocale, politica e istiturioni, Copanello, 2-4 giugno de 1987.

Hispania, LIX/2, núm. 202 (1999) 637-661 
llates desde 1857) le sucede en la representación (diputado en 1857, 1863, 1871, 1872 y 1876, además de senador vitalicio desde 1877); el hijo de éste, Germán, ejerce como diputado por Lugo en 1891 (además de presidente de la Diputación en la primera década del s. $\mathrm{XX}$ ), mientras que su hermano Nicolás es elegido varias veces representante lucense en el Congreso desde 1896 en adelante; un sobrino del Conde, Pastor Maseda y Vázquez de Parga, figura como presidente de la Diputación a lo largo del último decenio del s. XIX, en tanto que sus hermanos actúan como activos agentes electorales de Pallares en la zona de Vilalba y Begonte; su yerno Santiago Basanta Olano (casado con su hija Paz) aparece como un asiduo diputado provincial.., parientes directos a los que habría que añadir otros de carácter más indefinido y cuya caracterización concreta se nos escapa (aquellos que envían cartas al Conde encabezadas con el característico «Mi querido pariente y amigon) que proporcionan una muy sólida y fiel clientela a nivel municipal y provincial ${ }^{26}$.

Integrados de igual modo dentro del conjunto de las relaciones sociales con traducción en el ámbito político-electoral, están los contactos originados en los círculos de amistades. En este sentido, conviene recordar que la política decimonónica es un asunto de minorías, de un grupo restringido y selecto de procedencia, formación y medios de vida muy similares donde todos sus miembros se conocen y donde el papel reservado a las « masas» o a la « militancias es mínimo. Ese origen común que aporta un marcado sentimiento de identidad y unos idénticos espacios de socialización, la coincidencia en la Universidad (en los recurridos estudios de Derecho), unos contextos de interacción social compartidos (casinos, círculos, ateneos) y su ubicación en los estratos sociales elevados (por su mayoritaria condición de propietarios rentistas y/o titulares de respetadas profesiones liberales), convierten a la clase política en una elite que, más allá de las lógicas diferencias, comparte toda una serie de puntos en común. En un mundo así definido nada tiene de extraño que el recurso a las amistades (tanto a las recibidas por vía familiar como a las creadas gracias a la propia actividad vital) se convierta en una práctica generalizada en la búsqueda de apoyos y fidelidades clientelares: tanto la privatización de la política como la común preocupación por la defensa de unos mismos intereses de clase que une a los amigos, no hacen sino favorecer la colaboración ${ }^{27}$.

Práctica clientelat del favor, recurso a los contactos familiares y de parentesco, conversión de la amistad particular en amistad política ${ }^{28}$, son algunos de

26 Más información, en VejGa Alonso, X. R., O conde de..., cit. Para un ejemplo concreto de control de los cargos municipales por medio de grupos de parentesco, CARDESIN DiAZ, J. $M^{2}$ \& Lago PeNas, P., « Repensando el caciquismo: espacio político y agencia social en la Galicia de la Restauracióny: Historia y Crítica, 2 (1992) 191-226.

27 Para el contexto italiano, vid. MUSELLA, L, « Relazioni, clientele, gruppi e partiti nel controlo e nell'organizzazione della partecipazione polisica (1860-1914)", en MACRY, P. \& VILIANI, P. (a cura di), Storia dTialia. Le regioni dall Unità a oggi La Campania, Torino, Einaudi, 1990, págs. 733-790.

28 En el favor clientelar, la amistad y la familia sitúa M. StERra las bases principales del dominio político-electoral: « Partidos y líderes políticos en la Sevilla de la Restauración: conservadores y liberales»: Revista de Historia Contemparánea, 7 (1996) 67-102.

Higania, LIX/2, núm. 202 (1999) 637-661 
los medios activados para lograr la configuración de una facción capaz de competir con éxito en la lucha por el poder. En general, los tres elementos nos temiten con claridad al capital social que cada individuo consigue situar en su favor, al tiempo que evidencian la estrecha ligazón (dependencia) que la praxis política tiene con tespecto al conjunto de las relaciones sociales, apareciendo en ocasiones casi como una prolongación natural de las mismas ${ }^{29}$. Pero todo este elenco de situaciones no se dan en el vacío, no se producen en el seno de una sociedad carente de organización institucional. Bien al contrario, el Estado (acceder a sus órganos políticos de control) aparece como el referente último explicativo del activismo clientelar, un Estado que en absoluto se contenta con ser un simple escenario pasivo sino que adquiere un papel de actor protagonista. De este modo, el activismo gubernamental y las injerencias del ejecutivo resultan fundamentales para entender la actividad política de los años decimonónicos $y$, muy en especial, la dinámica electoral y el mantenimiento del favoritismo clientelar basado en un empleo torcido de los recursos administrativos, constituyéndose en otro de los factores a integrar en nuestro análisis ${ }^{30}$.

Así, evidencias como el encasillado, los candidatos oficiales y el apoyo moral del gobierno, la instrumentalización de la burocracia por parte del partido dominante en el ejecutivo, el empleo electoral de los subordinados jerárquicos del ministro de la Gobernación (gobernadores civiles, presidentes de diputaciones y alcaldes), el recurso al pucherazo o el empleo irregular del monopolio de la fuerza (detenciones arbitrarias de candidatos y electores de la oposición, formación de oficiosas partidas de la porra de actuación consentida por la Guardia Civil), nos recuerdan de modo permanente la capacidad estatal para dirigir en un determinado sentido el rumbo electoral. Sin embargo, conviene no hacer una lectura literal y unidireccional de este tipo de actuaciones que nos lleve a caer en el etror de pensar que en la España del XIX el Estado lo podía todo y que nada (hablando en términos político-electorales) se substraía a su control ${ }^{31}$. Hay que tener en cuenta que, más allá de una ordenación administrativa legalmente muy centralizada, la capacidad real de penetración tertitorial (infraestructural) del Estado decimonónico español era muy baja ${ }^{32}$, por lo que contar con el apoyo de los

29 ROMANELLI, R., "Sistemas electorales y estructuras sociales. El siglo XIX europeo», en FORNER, S. (coord.), Democracia, elecciones y modernización en Europa. Siglos XIX y XX, Madrid, Cátedra-Instituto de Cultura Juan Gil-Albert, 1997, pág. 38. La « deferencia» política colono/arrendatario-propietario de que tanto hablan los historiadores ingleses tiene mucho que ver con esta prolongación del liderazgo natural: $O^{\circ}$ GORMAN, $F$, «Electoral Deference in «Unreformed) England: 1760-1832w: The Journal of Modern History, 56 (1984) 391-429.

30 VARELA ORTEGA, J., « De los orígenes de la democracia en España, 1845-1923», en ForNER, S. (coord.), cit., págs. 129-201; SÁNCHÉ' MARroYo, F., « Los notables y el control político. Las elecciones parlamentatias en Extremadura durante la Restauración (1876-1886)m: Investigaciones Históricas, 13 (1993) 226, 236; RANZATO, G., "La forja de la soberania nacional: las elecciones en los sistemas liberales italiano y españob: Ayer, 3 (1991) 132-135.

31 Que es lo que hace, en buena medida, VAREL ORIEGA, J., "De los orígenes...», cit.

32 Riguer I PermanyER, B. de, « Nacionalidades y regiones. Problemas y líneas de investigación en torno a la débil nacionalización española del siglo XIX", en MORALES MoYA, A. \&

Hispania, LIX/2, núm. 202 (1999) 637-661 
poderes locales era fundamental a la hora de garantizar la reproducción del consenso. En función de esta visión, de una dirección original basada en la imposición centro-periferia pasamos a otra más entiquecida y compleja en la que ambas realidades interaccionan en un proceso no uniforme en el que el estudio casuístico debe de determinar la intensidad y la dirección predominante dentro del contacto, partiendo siempre de la consideración de que la negociación (en el matco temporal en el que nos movemos) se da siempre entre elites (centrales y periféricas) de intereses más coincidentes que divergentes ${ }^{33}$. Definir las cau-

EsTEBAN DE VEGA, M. (eds.), cit., pág. 81; Id., «Burgesos, polítics i cacis a la Catalunya de la Restauració»: L'avenf, 85 (1985) 26; Id., "La faiblesse du processus de construction nationale en Espagne au XIXème. siècle»: Revue d'bistoire moderne et contemporaine, 41-2 (1994) 353-366; FuS1 AizpurúA, J. P., "Centralismo y localismo: la formación del Estado español», en GoRTízır, G. (ed.), cit., págs. 77-90. Una perspectiva a nivel intemacional, en MANN, M., cit., págs. 596-623 (sólo a partir de 1870-80 aumenta la capacidad infraestructural de penetración del Estado en el territorio gracias, entre otras razones, a que sólo desde entonces la burocratización comienza a ser efectiva). Para el similar caso italiano, BEVILACQUA, P., « La dinamica degli interessi nel sistema liberale italiano da una prospettiva meridionales: Anales de la Universidad de Alicante. Historia Contemporánea, 7 (1989-90) 81 (" troppo Stato e Stato troppo debole»). Por otra parte, una gran cantidad de estudios aparecidos en los últimos años vienen a demostrar la importante capacidad de negociación de los notables locales con el Estado, y a desmentir por completo el tópico de la capacidad de éste para regir los destinos de la nación sin contar con las realidades locales de poder. Por ejemplo, Martínez Dorado, G., « La formación del Estado y la acción colectiva en España: 1808-1845": Historia Social, 15 (1993) 107-114; MARTi, M., "Els primers anys de la Restauració a Castelló de la Plana: les forces polítiques (1875-1891)n: Estudis d'bistòria contempo. rània del País Valencià, 6 (1985?) 222-228; SANCHEZ MANTERO, R, "La política y los políticos en la Andalucía Occidental durante la Restauración. Resultados de un proyecto de investigacións: Trocadero, 5 (1993) 9-15; PÉREz ArRibas, E., Politics i Cacics a Castello (1876-1901), Valencia, Edicions Alfons el Magnànim, 1988, págs. 44-45; CARASA Soto, P. (dir.), " Poder político, poder...», cit., pág. 143; TosCAS, E., « Les rapports entre lÉtat et les pouvoirs locaux en Catalogne (17801850): bilan des recherches», en DUPUY, R. (sous la direction du), Pouvoir Local et Révolution, 1780 1850. La frontiere interieure, Rennes, PUR, 1995, pág. 516. Las referencias se podrian multiplicar.

33 PÉrez PICAZo, $M^{2} T$., " Las transformaciones de la oligarquía murciana en el siglo XIX', en LAMBERT-GoRGES, M. (ed.), Les élites locales et l'état dans lEspagne moderne du XVTème. au XIXème. siècle, Paris, CNRS, 1993, págs. 331, 335; SANZ LeGarisn, P., Alava, "el cacique» y los politicos, Vitoria-Gasteiz, Diputación Foral, 1992, pág. 32; Forner, S. \& GARCiA, M., cit., pág. 8; ÁlvareZ JunCO, J., « Redes locales, lealtades tradicionales y nuevas identidades colectivas en la España del siglo XIẌ), en Robles EgEA, A. (comp), cit., pág. 71; SIERRA, M., «a polititica deh.., cit., pág. 86; ZuJuTA ALDEguer, R., Notables, politicos y clientes. La politica conseruadora en Alicante. 1875-1898, Alicante, Generalitat Valenciana-Instituto de Cultura « Juan Gil-Alberb», 1996, págs. 23, 41. La referencia obligada para el estudio de las relaciones centro-periferia es TARrow, S., Tra centro e periferia. I/ ruolo degli amministratori locali in Italia e in Francia, Bologna, il Mulino, 1979 (establece la interrelación como un problema de alianza entre elite central y elementos escogidos de la periferia). Ver también, LUPO, S., "Tra centro e periferia. Sui modi dell'aggregazione politica nel Mezzogiorno contemporaneo»: Meridiana, 2 (1988) 13-50; MUSEJ.LA, L, «Clientelismo e relazioni politiche nel Mezzogiomo fra Otto e Novecentom; ibid., pág. 78; ALMEIDA, P. T. de, " Reformas electorales y dinámica política en el Portugal liberal (1851-1910)», en ForNER, S. (coord.), cit., pág. 105. 
sas que explican la existencia (o inexistencia) de prohombres locales que actúen a nivel de distrito o de provincia con capacidad de presión y negociación frente a Madrid, sería lo más útil e históricamente correcto. La única condición para llevar a cabo este análisis es huir del tópico facilón y de cualquier apriorismo rígido de partida: por ejemplo, considerat el turno testaurador una imposición del centro que hace y deshace a su antojo en el ámbito local sería un fuerte condicionante negativo del estudio, ya que tal alternancia puede responder de hecho a una situación de equilibrio real entre las facciones clientelares con presencia en el distrito que prefieren acudir al usufructo periódico del poder antes que dirimir la supremacía en una lucha abierta de siempre inciertos resultados. En estos casos el turno sería más la confirmación de una colaboración establecida en la periferia que el resultado lógico y lineal de la fortaleza del centro ${ }^{34}$.

34 Es lo que ocurre, por ejemplo, en la circunscripción de Lugo (que engloba los antiguos distritos de Lugo, Vilalba y Sartia) a lo largo del último tercio del siglo XIX, donde la perfecta alternancia liberales-conservadores (dos diputados ministeriales por uno de la oposición, como resultado permanente) responde al implícito pacto entre las dos redes clientelares de mayor presencia en la zona: las encabezadas, respectivamente, por el conde de Pallares (conservador) y Benigno Quiroga López-Ballesteros (liberal). Ver, VEIG ALonso, X. R., O conde de..., cit., págs. 420-463. El caso del turno no es el único en el que, con demasiada ligereza, se da por supuesta la supremacía de las negociaciones y del poder de imposición ubicados en el centro del sistema. Lo mismo ocurre, por ejemplo, con el papel otorgado a los funcionarios, cuyo gubernamentalismo se entiende casi como una realidad obvia cuando de hecho su actuación puede ser más resultado de la fidelidad al patrón de turno que al propio Estado, conscientes como son de debet su puesto de trabajo a las gestiones privadas del primero. Ejemplos de esta situación, en: Veiga Alonso, X. R., cit., pág. 221; TARRow, S., cit., págs. 54-55; Romanelli, R, « Le regole del...», cit., pág. 703. Son, es claro, los riesgos de fomentar una administración privatizada y dependiente de criterios personales e informales (la recomendación y el enchufísmo) genetadotes de fidelidades igualmente particularizadas, y no un organismo neutro basado en pautas públicas y meritocráticas que si contribuirían a una interiorización del Estado en la conciencia de sus empleados. Y lo mismo que de los funcionarios se puede afirmar de los cuneros. La investigación ha tendido a comprenderlos como la qu intaesencia de un poder central que logra imponerse a los distritos situando candidatos por completo extraños a la realidad local, cuando la situación que representan puede ser justamente la contraria: la de unos poderes locales con el control suficiente sobre sus espacios de actuación como para hacer elegir en ellos a aspirantes de los que nadie había oído hablar. Éstos pueden ser desde simples testaferros que actúan bajo cuerda y en estrecha dependencia de los poderes de que depende su elección, hasta individuos con muy buenos contactos en el centro del sistema que se encargan de intermediar las gestiones solicitadas desde los ámbitos locales. En todo caso, unos muy útiles dipurados cuneros que nunca (por su carencia de arraigo directo en los distritos donde resultan electos) pondrán en cuestión el monopolio de poder de sus patrocinadores locales. Ver, PÉREZ ARRIBAS, E., cit,, págs. 45-46; DíEz CANO, L-S., « Representación parlamentaria y poder económico en la Restauración: el caso salmantinom, en AA.VV., Las Cortes de Castilla y León, 1188-1988, v. Il, Valladolid, Cortes de Castilla y León, 1990, pág. 490; CREspillo CARréGALO, Elecciones y partidos politicos en Málaga (1890-1901), Málaga, Diputación, 1990, pág. 63; CArASA Soro, P., «Élites castellanas đe...», cit., pág. 195; SIERu $\mathrm{M}^{3}$, «La politica del.., cit., pág. 221; MORENO LuzÓN, J., « El conde de...», cit., pág. 163; Serrano Garcí , R. \& Pel.Az López, J. V., "Los parlamentarios leoneses en la Restauración: Investigaciones Histónicas, 15 (1995) 72.

Hi.puna, LIX/2, núm. 202 (1999) 637-661 
Para terminar con la presentación de los elementos determinantes de la política clientelar, y luego de haber repasado tanto los que tienen su origen en las estructuras sociales como los derivados de la ordenación político-administrativa estatal (con las matizaciones introducidas), resta todavía por integrar en el discurso un último componente de problemática consideración cual es el factor económico. A pesar de que determinados estudios entienden la política como una realidad ajena a las relaciones de producción dominantes e intentan situarla en un nivel por completo autónomo e independiente (casi ideal e incontagiado por el medio), resulta evidente la estrecha influencia que, para el período considerado en este trabajo, ejercen las realidades económicas en la definición de las estrategias políticas, hasta el punto que la divisoria entre ciudadanos electoralmente activos y electoralmente inactivos la marca un criterio $100 \%$ económico como es el cupo impositivo satisfecho. Dentro de las redes clientelares, la componente económica aparece como uno de los hilos que engarza a los patronos y subpatronos con sus respectivas clientelas, si bien el grado de importancia de la misma varía en función del momento histórico en que el estudio se sitúe. Así, en situaciones de sufragio restringido, la relativa homogeneidad socioeconómica de los actores que participan en el juego político (los privilegiados del censo y la educación, las capacidades) hace que las diferencias entre ellos se minimicen al aparecer igualados por arriba y clasificados dentro del común denominador de grupo dominante. Por lo tanto, la incidencia de factores tan desequilibradores como la subordinación económica parece, en principio, de escasa trascendencia, cediendo protagonismo en cuanto al papel de cohesionadores internos de la red al otro tipo de variables (más propiamente clientelares) ya repasadas ${ }^{35}$. No obstante lo anterior, el estudio al microscopio de las clientelas gestadas bajo el condicionante del censo aporta algún dato interesante que arroja dudas sobre esta afirmación. Así, hay que tener en cuenta que dentro de la homogeneidad que preside el colectivo de los individuos con derecho a voto, la gama de situaciones personales puede ser muy amplia e incluir realidades de dependencia económica entre ellos con una más que potencial traducción en apoyo político ${ }^{36}$; del mismo modo, no se puede olvidar que la caracterización de notable local (de la que participan una parte variable pero amplia de ese selecto grupo de votantes) descansa, en buena medida, en el reconocimiento social por parte de la comunidad de tal condición, para lo

35 Como afirma el profesor C. DARDÉ: «(...) dadas las condiciones generales de los electores con la ley de sufragio censitario -fundamentalmente su independencia económica- parece lógico pensar en una influencia basada en el acuerdo más que en la coacción, en el consentimiento más que en la violencia; es decir en la existencia de clientelas políticas en torno a uno o vatios personajes locales...». Ver, «El sufragio universal en España: causas y efectos»: Anales de la Universidad de Alicante. Historia Contemporánea, 7 (1989-90) 89.

36 Es lo que ocurre con determinados elementos de la clientela mindoniense del conde de Pallares que, con ocasión de las elecciones de 1863 (recordemos, sufragio censitario), no dudan en presionar a votantes respecto de los que mantienen una posición de preeminencia por su carácter de prestamistas y de perceptores de rentas. Ver, VEIGA ALONSO, X. R., $O$ conde de..., cit., págs. 215-216.

Hitomaniu, LIX/2, núm. 202 (1999) 637-661 
cual ser titular de una informal microclientela resulta fundamental. Estas clientelas locales pueden no tener traducción electoral directa (si sus integrantes carecen de derecho al voto), pero sí un importante significado sociopolítico por cuanto dotan a su patrón titular de una proyección y prestigio públicos básicos en su presentación como hombre político, sin que pueda en absoluto descartarse la existencia de ligaduras de tipo económico entre éste y aquéllas (más bien todo lo contrario) ${ }^{37}$.

Si de lo que es un contexto de sufragio censitario pasamos a otro definido por una acceso general (masculino) al voto, la importancia del factor económico no hace sino acrecentarse. Parece lógico pensar que con un electorado muy ampliado las dificultades para continuar ejerciendo un control sobre él aumentan, aunque sólo sea por la evidencia de tener que tomar en consideración un mayor número de potenciales votantes ( $y$ ésto tanto para ejercer una acción movilizadora como desmovilizadora) ${ }^{38}$. En consecuencia, y dado que el acceso al voto adquiere un carácter general, se necesitan arbitrar mecanismos de igual modo capaces de ejercer una acción estructural con el suficiente potencial como para abarcar una gran masa de electores: el recurso a la instrumentalización político-electoral de las relaciones económicas se presenta como el más cercano e inmediato (junto al incremento y la regulatización de la presión gubernamental), una vez que la práctica del favoritismo clientelar y la de la prolongación-traducción política de las relaciones familiares y sociales demuestran sus limitaciones con la nueva ordenación del sufragio. Por lo tanto, y en función de la mayoritaria condición agrícola de la economía española tanto en los años del Sexenio como en los posteriores a 1890, las relaciones de producción dominantes en el campo y las enormes desigualdades que generan pasan a tener un protagonismo directo e inmediato en la definición de las estrategias políticas y de los medios puestos en práctica para asegurar los resultados electorales: foreiros gallegos, arrendatarios castellanos, jornaleros andaluces, rabassaires catalanes... son ahora depositarios de un voto que, bien sea para ejercer una acción en positivo (votar) o en negativo (abstenerse), hay que intentar dirigir en la dirección adecuada y nada mejor para hacerlo que utilizar la supremacía económica que sobre ellos mantienen propietarios y percep-

37 De hecho, el cuidado de estas microclientelas locales era fundamental para que los notables mantuvieran su condición de tales frente a la comunidad en general y a sus iguales (y competidores) en particular, de ahí su enfado cuando el diputado de turno al que habían apoyado en las elecciones no cumplía con su parte del trato clientelar gestionando favores en su beneficio. Ver, por ejemplo, carta de F. Lago a Pallares (17-II-1860): AHPL, CP, leg. 9.

38 Como afirmaba R. García Blanes al conde de Pallares (4-III-1871: AHPL, CP, leg. 10): «Con el dichoso Sufragio Universal es necesaria una organización bien entendida, como V. sabe, y contat con que se distribuyan los agentes, que por más que se quieran evitar, tienen que ser muchos». Insiste en la misma idea R. Pardo Montero también en una correspondencia dirigida al Conde (24-X-1870: ibid.): «(...) si los electores fueran limitados, poco o nada harian; como es todo el pueblo y les predicaron contra contribuciones, quintas, maestros, médicos, etc., etc., y hasta imputándonos la causa de todo mal, el populacho cree, y siempre llevarán consigo más de lo que uno piensen.

Hipunia, LIX/2, núm. 202 (1999) 637-661 
tores de rentas ${ }^{39}$. El problema que se plantea al tomar en consideración la subordinación económica como otro de los sumandos a añadir en la ya larga lista de los condicionantes explicativos del voto, es el de su caracterización como mecanismo de tipología clientelar. $Y$ ésto porque mientras que el intercambio mutuamente beneficioso (base del clientelismo) se hace visible con más o menos claridad en los contactos patrón-cliente bajo el sufragio censitario, o aparece explícito en el caso de los beneficiados con una colocación en cualquier oficina provincial de cualquier dependencia ministerial (por ejemplo), no resulta tan evidente, si es que existe, cuando el supuesto implicado es un casero o un arrendatario al que el administrador del absentista de turno ordena votar por determinado candidato ${ }^{40}$ : ¿cuál es, en este caso, el beneficio que recibe a cambio de su voto? iEs éste un contacto clientelar ou una simple relación de subordinación disfrazada con una mínima dosis de patronazgo? ¿Lo explica todo la deferencia natural cultivador-propietario? En el siguiente y último epigrafe intentaremos situar mejor los términos del problema.

39 Gómez Cabornero, S., «Poder político y territorio electoral en la Restauración: el caso de la familia parlamentaria Rodríguez en Zamoras: Investigaciones Históricas, 16 (1996) 95-96; RAMOS, $M^{2}$ D., «El Estado-Padrino: Caciquismo y redes caciquiles en Andalucía Oriental durante la Restauración»: Trocadero, 5 (1993) 57; PLÑarubia I Marquiss, I., "«Caciquisme» e democratizzazione a Maiorcas: Spagna contemporanea, 6 (1996) 7, 16-17; DuRán, J. A., Crónicas 1. Agitadores, poetas, caciques, bandoleros y reformadores en Galicia, Madrid, Akal, 1974, pág. 248; Id. (ed.), Aldeas, aldeanos y labriegos en la Galicia tradicional, Madrid, MAPA-Xunta de Galicia, 1984, pág. 79; VEIGA Alonso, X. R., O conde de..., cit., págs. 274-279; CRUZ ARTACHO, S., Caciques y campesinos..., cit.; COBo Romero, F. et al., «El poder municipal como fuente de privilegio socials: VI retunión del $S_{e-}$ minario de Historia Agraria, Cabezón de la Sal (Cantabria), 1-3 diciembre de 1993, págs. 103-111; Garrido MArTíN, A., "Clientelismo y localismo en la vida política de Cantabria, 1875-1931», en Montesino Gonzilez, A. (ed.), cit., págs. 241, 251; MArTínez MAr'tin, M. et al, cit.; Rulz Pt́. REz, R. \& R., cit, págs. 206, 213; YANINI, A., El caciquisme, cit.; LrTTELTON, N. A. O., «El pattonazgo en la Italia de Gioliti (1892-1924)»: Revista de Occidente, 127 (1973) 94; BICCI, A., «Lo scrutinio di lista e la sopravvivenza dello spirito campanilistico. Il caso del terzo collegio di Firenzew: Rassegna storica toscana, 1 (1996) 153; PAVONE, C., "L'avvento del suffragio universale in Italias: Annali della Fondazione Lelio e Lisli Basso, 9 (1987-88) 99-100; FRANZINA, E., «Le strutture elementari della clientelas, en CAMurRI, R. (a cusa di), La Scienza moderata. Fedele Lampertico e /ItaLia liberale, Milano, Franco Angeli, 1992, págs. 396-397; J ESSENNE, J-P., Pouvoir au village at Rétolution: Artois, 1760-1840, Lille, PUL, 1987; Dunbabin, J. P., «Le riformi elettorali e le loro conseguence nel Regno Unito, 1865-1895", en POMBEN, P. (a cura di), La trasformazione politica.., cit., pág. 124; Hoppen, K. T., (Le elites e l'influenza elettorale in Irlanda, 1800-1918n: Quaderni storici, 69 (1988) 793-797; CAMmARANo, F., «Logiche comunitarie e associazionismo politico neIla Gran Bretagna tardovittoriana: procedure elettorali e «corruzionem»: ibid., págs. 847-849; Newby, H. et al, Property, Paternalism and Power. Class and Control in Rural England, London, Hutchinson, 1978. Lo mismo se puede afirmar respecto del control electoral protagonizado por dueños de establecimientos fabriles: PEÑA GuerRERO, $M^{2}$ A., "Caciquismo y poder empresarial. El papel político de las compañías mineras en la provincia de Huelva (1898-1923)): Trocadero, 5 (1993) 299-324; AlBAREDa, J. \& Figuerola, J., «Una visió de la comarca d'Osona: anàlisi del control social en una comarca d'economia dualy, en MrR, C. (ed), Actituds politigues $i$ control social a la Catalunya de la Restauració (1875-1923), Lleida, Virgili \& Pagès, 1989, pág. 181; Garuido MARTín, A., Favor e indifferencia..., cit., pág. 206. 


\section{CARACTERIZACIÓN INTERNA DE LAS CLIENTELAS: DEL NÚCLEO A LA PERIFERIA DE LA RED}

Delimitar la composición socioeconómica de las pirámides o redes clientelares (o de su inmediata plasmación política, la facción) no es una tarea fácil por su presentación segmental que atraviesa las batreras clasistas incluyendo en su seno a individuos de muy diferente condición. Un primer elemento a definir es el constituido por el patrón-broker, elemento neurálgico de la red y constructor y aglutinador básico de la misma ${ }^{41}$. Su función aparece muy clara: lograr beneficios particularizados para los integrantes de su clientela, bien sea recurriendo a la movilización de recursos de primer orden de los que dispone directamente (tierra, ganado, financiamiento, promoción en sus negocios particulares...), bien a recursos de segundo orden que no posee en propiedad pero a los que tiene acceso por medio de terceros (los puestos en la administración estatal o la recomendación a amigos particulares son las dos actuaciones más repetidas): en el primer caso actúa propiamente como patrón; en el segundo como broker, como intermediario ${ }^{42}$. En nuestro esquema, el cacique aparece esencialmente como un mediador, como un intermediario que tiene en esta posición uno de sus principales baluartes (ocupando una ubicación que, en un sistema liberaldemocrático y socialmente desarrollado, corresponderia a organizaciones surgidas de la sociedad civil articulada y a una burocracia neutra y apartidista): situado a medio camino entre el centro y la lejana periferia, cuenta con contactos en los dos espacios y éste es el principal argumento en el que basa su supremacía. De hecho, intenta por todos los medios mantener la separación gobernantes-gobernados y monopolizarla en su beneficio para de este modo perpetuarse en su papel central ${ }^{43}$. En consecuencia, un primer rasgo caracterís-

40 «Guevara supongo tenga ya dado orden a los caseros del partido»; «D. Eduardo Berdes de quien es administrador Aallo de Sistallo (...), cno pondría sus caseros a disposición de la oposición h); «Hoy como día de feria di orden a todos mis casetos (...) para que en la próxima elección de diputado, voten al St. Conde de Pallares»... Los ejemplos del control absoluto sobre los votos de caseros, foretos y artendatarios podrían multiplicarse. Las referencias concretas, en Vejga Alonso, X. R., O conde de..., cit., pág. 275.

41 La idea de las facciones clientelares como constructos del patrón, en ALAvi, $\mathrm{H}$, cit., pág. 92; MAYER, A. C., cit., pág. 109.

42 La diferenciación entre recursos de primero y de segundo orden, en BorssevaIN, J. Friends of Friends..., cit., págs. 147-148; PISELL, F, «Reti sociali e comunicative», en Id. (a cura dis), cit., pág. XXIX; Mniz, R., «Estructura y acción..,», cit., pág. 198.

${ }_{43}$ CARASA, P. (dir.), Élites castellanas de..., pág. 18; GOEJE, H. de, «El cacique como spolitical middleman». El poder local en el concejo de Ponga (Asturias), 1900-1923n, en FERnÁndez Prieto, L. et al., cit., págs. 393-413; Romero Maura, J., cit., pág. 26; Peñarrubia I Marquès, I., "Control caciquil i projectes populars. El cas de Mallorca a l'època de la Restauració): Estudis d'bistòria agrària, 10 (1994) 131; Riquer, B. de, «Burgesos, polítics i...», cit., pág. 26; GeIINER, E., "Patrones y Clientes», en Id., cit., págs. 14-15; GrJBAud, G., Mediatori. Antropologia del potere democristiano nel Mexrogiorno, Torino, Rosenberg \& Sellier, 1980, págs. 63-70; MerIGGt, M., «La borghesia italianar, en KoCKA, J. (a cura di), Borghesie europee dell Ottocento, Venezia, Marsilio, 1989, pág. 174; MUSELLA, L, Individui, amici, clienti. Relaqioni personali e circuiti politici in Italia meridionale tra-

Hispania, LIX/2, nưm. 202 (1999) 637-661 
tico de los titulares de redes clientelares es su capacidad para disponer de relaciones privilegiadas tanto en el nivel local como en el central, lo que incluye a su vez la pertenencia (informal) a alguno de los colectivos organizados en torno a las grandes figuras de la política nacional que son las que garantizan una buena conexión madrileña ${ }^{44}$.

Junto a esta, llamémosle, elevada capacidad de negociación a dos bandas (típica del broker), los patronos suelen gozar de una destacada posición económica por lo general asentada en propiedades territoriales (típica del notable). Hay que tener en cuenta que la propiedad (y muy en especial la posesión de tietras), para el arco temporal decimonónico en que nos situamos, representa una precondición de suma importancia en la actividad política: determina legalmente la posibilidad de acceder a ella, otorga prestigio ante la comunidad, permite convertir la práctica política en una prolongación natural del liderazgo social asentado en la tierra, asegura una conexión directa con el elitista y decisivo colectivo de propietarios, garantiza el apoyo electoral de los colonos cultivadores... ${ }^{45}$. Del mismo modo, la tradición familiar y el hecho de contar con antepasados de destacada actividad pública es otro de los elementos que facilita la asunción de un papel dirigente, no tan sólo por tecibir una clientela ya conformada sino por aparecer el nuevo político como depositario de un poder legitimado en la tradición y la costumbre y recubierto del prestigio y la respetabilidad que otorga la historia: las abundantes sagas políticas que pueblan el siglo XIX español son la mejor prueba. Sin embargo, ninguna de estas tres

otto e novecento, Bologna, il Mulino, 1994, pag. 66; ZANE, M., «Associazionismo e politica fra otto e novecento in un paese delle colline bresciane»: Quaderni storici, 26 (1991) 518; RiNAuDo, Y. «Un équilibre méditerranéen?: Le pouvoir local entre I'État et le territoiren: Études rurales, 101-102 (1986) 209; ABÉLĖs, M., «Pouvoirs dans la commune, pouvoirs sur la commune»: ibid., 93-94 (1984) 326.

44 Una relación evidente, por ejemplo, en el caso de los titulares de redes clientelares que actúan en la provincia de Lugo: Cándido Martínez (diputado por Mondoñedo entre 18811889) con Sagasta; el conde de Pallares (por Vilalba en 1876 y senador vitalicio desde 1877) con Cánovas y Fernando Cos-Gayón; Benigno Quiroga López Ballesteros (por Lugo entre 18811905) con Segismundo Moret; Francisco Sanz (por Viveiro en 1881, 1886) con Sagasta; Constantino Velarde Pla (por Chantada en 1899) con Silvela; Dositeo Neira Gayoso (senador en varias ocasiones) o Avelino Montero Villegas (por Mondoñedo en los primeros años del s. XX) con Montero Ríos...

45 Son innumerables los estudiosos que han destacado la estrecha ligazón existente entre actividad política y fortaleza económica. Por ejemplo: MERINERo Martín, M² J. \& SÁnCIEZ MARROYO, F., «El monopolio del poder en la Extremadura Contemporáneas: Espacio, Tiempo y Forma, 3 (1990) 101-117; RAMOs, M D., cit., pág. 48; MORENo LuzóN, J., «Teoría del clientelismo...», cit., págs. 198-199 (con critica incluida a Romero Mauta por su apresuramiento en desligar caciquismo y tiqueza); BARREDA FonTES, J. M . $^{2}$ cit., pág. 68; PEÑA Guerrero, $\mathrm{M}^{2} \mathrm{~A}$., El sistema caciguil..., cit., págs. 75-77; Carasa Soto, P. \& Diez CANo, L-S., cit., págs. 46-47; Sierra, M² La familia Ybarra, empresarios y politicos, Sevilla, Muñoz Moya y Montraveta, 1992; CARNERo ArBat, T., «Economia y poder político en el País Valenciano, 1870-1914): Debats, 8 (1984) 7; VILLA ARRANZ, J., «La base social del poder de una elite en el primer tercio del siglo XX: Invertigaciones Históricas, 15 (1995) 30; Hidalgo Marin, I. S., cit., págs. 113-115.

1Hippania, LIX/2, núm. 202 (1999) 637-661 
precondiciones (relaciones y contactos, cuantitativa y cualitativamente, amplias, fortaleza económica y tradición familiar... a las que se podrían añadir algunas otras como el prestigio ganado en el desempeño de la actividad profesional con posibilidad de tener una proyección política, por ejemplo) garantizan que un individuo ejerza efectivamente como patrón, y ésto porque al poder y al saber (la gran presencia de abogados en las Cortes tiene mucho que ver con este último criterio) debemos de añadir un componente altamente casuístico de obligada consideración como es el querer, la voluntad de ejercer una función de patronazgo ${ }^{46}$ : sólo así se explica que, a partir de condicionantes estructurales muy similares, en determinadas áreas aparezcan prohombres de gran arraigo y fortaleza, dominadores casi absolutos de sus respectivos distritos y con gran fuerza de negociación con el centro, y en otros no. La reunión de esta setie de requisitos conformaría el patrón ideal, lo cual, evidentemente, no quiere decir que sea un modelo universalmente extensible: habrá casos en los que las citadas características se den cita en el mismo actor dotándolo de una gran capacidad de atracción clientelar ${ }^{47}$, ottos en los que una de ellas sea la claramente predominante $y$, como no, otros que escapen a la tipología propuesta, que no obstante entiendo puede resultar de alguna utilidad en la identificación del proceso de creación de los patronos clientelares.

Dar el salto cuantitativo que supone pasar de la definición del elemento central de la red a intentar el mismo proceso respecto del conjunto de sus integrantes, es ya harina de otro costal. La propia indefinición de las clientelas por su carácter no formalizado y casi siempre estrictamente privado, hace que el simple conocimiento de sus integrantes sea ya de por sí una tarea dificil de abordar. Para poder avanzar en este camino el acceso a documentación privada suele resultar crucial, por cuanto en la correspondencia se ven reflejados aquellos individuos que mantienen un más intenso y directo contacto con el líder. Incluso así, sólo el núcleo de la red más cercano al patrón es el que se presenta a nuestros ojos, en tanto que los elementos situados en la periferia (relacionados con el centro a través de contactos indirectos) permanecen inmersos en una neblina que dificulta su visión y caracterización. Nuestro estudio de los individuos ubicados en la zona supetior de la pirámide clientelar construida por el conde de Pallares (político conservador lucense, diputado en cinco ocasiones y senador vitalicio desde 1877) permite definirlos como actores dotados de poder,

46 Romero Salvador, C., «Estado débil, oligarquias fuertes, o «las palabras para el gobernador, los votos para el obispom, en FERNÁNDEZ PRIETO, L. et al., cit., págs. 148-152; YANINI, A., El caciguisme, cit., pág. 18; MORENo LuzóN, J., «Romanones: conquistador de...», cit., pág. 283; Borssevain, J., «Manipolatori sociali: mediatori come imprenditorì, en PISELLI, F. (a cura di), cit., págs. 257, 260.

${ }_{47}$ El conde de Pallares varias vecés citado seria un buen ejemplo de patrón completo: tradición politica familiar (su padre fue diputado en las Cortes de Cádiz; su suegro entre 1837-40), mayor contribuyente en los municipios de Vilalba y Lugo y buenos contactos madrileños en las figuras de Cánovas y Cos-Gayón (que garantizan un trato favorable en las relaciones con la administración).

Hijpania, LIX/2, num. 202 (1999) 637-661 
entendido éste en su sentido más genérico de capacidad para influir en las decisiones de terceros. Así, en una elevada proporción, aparecen integrados en el selectivo grupo de los medianos y mayores contribuyentes de sus respectivos municipios (bien personalmente, bien por pertenecer a familias de sólida posición económica ${ }^{48}$. La ocupación de cargos públicos es una segunda característica, que en el caso de titulares de alcaldías y concejalías presenta un cierto carácter endogámico con apellidos que se repiten durante décadas y que evidencian una visible continuidad en el disfrute del poder institucional local; la casuística se completa con la presencia de diputados a Cortes, gobernadores civiles, presidentes y secretarios de la Diputación, diputados provinciales, jueces y fiscales municipales y administradores de rentas estancadas ${ }^{49}$. Por último, la tipología de este núcleo clientelar se cierra con la generosa presencia de las profesiones liberales, abogados con marcada preferencia, aunque también médicos, notarios y farmacéuticos (sin que falten tampoco sacerdotes), muchos de ellos titulares de espacios institucionales de poder y, a menudo, definidos en los censos y padrones acompañados del calificativo de propietario sin que muchas veces sea posible discernir cual de las ocupaciones es la preponderante. En todo caso, individuos que por detentar funciones socialmente muy valoradas (entre otras razones por su escasez en el rural lucense) gozan de prestigio e influencia en el contexto local, de un peso decisivo dentro de la comunidad que la ocupación de cargos públicos y la posesión de tierras no hacen sino incrementar ${ }^{50}$. Resulta obvio resaltat la capacidad de poder movilizador que reúne

48 Esta dimensión familiar es un factor a tener siempre en consideración en cualquier análisis referido a la política decimonónica, por cuanto el individuo se define dentro de la comunidad, mucho más que por su individualidad, en relación con el grupo familiar de referencia, por lo que en muchas ocasiones su arraigo y poder locales vienen expresados más (y se explican mejor) por esta dimensión de parentesco que no por su singularidad entendida en sentido estricto. El estudio económico está basado en la consulta de los Repartimientos de la Contribución Territorial de la provincia de Lugo correspondientes a la segunda mitad del s. XIX. Una información más completa, en VEIGA ALONSO, X. R., O conde de..., cit., págs. 408-411.

49 Diputados a Cortes identificados como miembros de la clientela pallaresca son Casiano Pérez Batallón Losada $(1879,1884)$ José M² Pardo Montenegro (1879), Germán y Nicolás Vázquez de Parga (1891; 1896 y 1899-1907, respectivamente); gobernadores civiles (Antonio de Medina Canals); presidentes de la Diputación (Miguel Rodriguez Guerra, Antonio Camba, Pastor Maseda Vázquez de Parga, Germán Vázquez de Parga); secretarios de la Diputación (Pedro González Maseda); diputados provinciales (Santiago Basanta Olano, Ramón Pardo Monteto, Manuel Freire Calviño, Andrés Basanta Olano, Manuel Pardo Valcárcel...); alcaldes (Andrés Basanta Olano, José Santomé y Antonio Rico, de Vilalba; Domingo Corredoira, de Begonte; Manuel Basanta, de Castro de Rey; José Sanjurjo Sánchez, de Outeiro de Rey; Manuel López Castro, de As Nogais...); jueces y fiscales municipales (Ramón Pardo Montero, de Trasparga; José Maseda Vázquez de Parga, de Begonte); administradores de estancadas (Antonio Sanjurjo, de Vilalba; José Portas, de Castro de Rey; José de Parga, de Mondonedo)... Una relación más completa y exhaustiva, en VEIGA ALONSO, X. R., O conde de..., cit., págs. 404-411.

50 Por ejemplo: J. Ma Castro Bolaño (abogado, diputado provincial, propietario), Antonio Camba (abogado, presidente de la Diputación, diputado provincial, propietario), Andrés Basanta Olano (farmacéutico, alcalde), Santiago Basanta Olano (abogado, notario, diputado pro-

Hitpania, LIX/2, núm. 202 (1999) 637-661 
un colectivo así definido, que concentra en su seno tres de las más importantes fuentes de poder: la económica, la político-institucional y la social ${ }^{51}$.

Identificada y caracterizada tanto la cabeza rectora como el elitista núcleo de la red, resta todavía por conocer y definir el conjunto de los seguidores que integran la periferia del complejo reticular $(o$, si se prefiere, la base de la pirámide clientelar). Si ya antes advertíamos de la dificultad para realizar este trabajo respecto de los clientes más cercanos al patrón, ahora esas dificultades se ven en gran medida incrementadas porque la relación entre éste y sus bases o bien nos son desconocidas, o bien aparecen intermediadas por los componentes del núcleo en su calidad de titulares de microclientelas. En consecuencia, las siguientes reflexiones tienen más de hipótesis a comprobar que de presentación de resultados avalados por el trabajo empírico, y así deben de ser entendidas y valoradas. En primer lugar, parece muy aconsejable marcar una primera y clara división entre incluidos/excluidos de las redes clientelares, por cuanto entendemos que no puede valorarse el vínculo clientelar a partir de una consideración extensiva que lo presente como capaz de abarcar al conjunto de la población, y ésto por una razón muy simple: el clientelismo está basado en la discriminación, el favoritismo y el reparto desigual de beneficios, por lo que un cliente sólo se contemplará a sí mismo como positivamente discriminado, favorecido en el trato y beneficiado en el reparto si es consciente de que otros no lo son, de que otros sufren estas situaciones en negativo ${ }^{52}$. Pero incluso dentro de los integrados la homogeneidad es más aparente que real. Así, habría que establecer una nueva cesura dentro de éstos en función de la cantidad y calidad del beneficio obtenido en el intercambio. Por un lado, aquéllos que son capaces de transmitir por escrito sus demandas (alfabetos), que reclaman puestos para los que es preciso un mínimo nivel de formación (dotados de educación letrada más o menos amplia) y que, cuando menos en potencia, están en disposición de situarse como burócratas, administradores de propietarios absentistas o titulares de iglesiarios, por poner algunos ejemplos. En estos casos, nos estamos refiriendo a una clientela que es capaz de aprovechar su acceso a las infraes-

vincial), Ramón Pardo Montero (abogado, alcalde, juez municipal, diputado provincial, propietario), Manuel Basanta (abogado, notario, propietario), José de Parga (abogado, propietario, administrador de estancadas), José Jorge de la Peña (médico, propietario), Andrés Olano Silvá (abogado, notario, secretario del juzgado)...

51 Sobre el tema central de las fuentes de poder: ManN, M., cit.; Bobiso, N., Estado, Gobierno y Sociedad. Por una teoria general de la politica, México, FCE, 1989, págs. 104-114.

52 Martínigz Al.jer, J., "Patrons i clients»: Recerques, 9 (1979) 157; Litn.ewood, P., «Campesinos, producción y patronazgo: un marco alternativo para analizar la relación upatrón-cliente" en las sociedades campesinas mediterráneas»: Agricultura y Sociedad, 13 (1979) 175; Moriso LuZȮ́N, J., "Teoria del clientelismo...», cit, pág. 208. Además, hay que tener en cuenta que la pertenencia a una clientela es selectiva, que el potencial cliente debe ser capaz de ofrecer algo al patrón de turno a cambio de su protección (situación que se agraba por la evidencia de un elevado número de clientes demandantes frente a uno mucho más restringido de patrones). Ver, VEICA ALONSO, X. R., “Los marcos sociales...», cit;; Scotr, J., «Patronazgo o explotación», en GEJ.L.NER, E., cit., págs. 56-57.

Ilippunia, LIX/2, núm. 202 (1999) 637-661 
tructuras educativas (y su disponibilidad de contactos personales privilegiados) para promocionarse socialmente y sacar tajada en el reparto de la tarta clientelar, un colectivo de ¿clases medias urbanas? ¿pequeña burguesia? que la investigación tiene todavía pendiente de analizar y que algunos autores presentan como claros beneficiados del sistema caciquil ${ }^{53}$.

Peto junto a éstos, están los actores anónimos que conforman la base de la pirámide clientelar, los que apenas si aparecen en las cartas recibidas por el patrón, los que no transmiten por escrito sus demandas, los que no tienen acceso a los canales educativos, los que catecen de formación y no pueden aspirar a formar parte de la aristoctacia trabajadora de cuello blanco; en el caso gallego (y de gran parte del Estado) el omnipresente campesinado que recibe las órdenes de los amos para dirigir el voto en determinada dirección: ¿cuál es el pago que obtienen a cambio de su apoyo? ¿existe en este contacto tan marcadamente desigual el componente de beneficio mutuo? ¿es ésta una relación propiamente clientelar o una simple traducción política de la subordinación económica? ¿podemos seguir hablando en estos casos de clientelismo y patronazgo o debemos hacerlo de dominación pura y simple? Algunos estudiosos han lanzado la hipótesis de un campesinado que, en su casi infinita capacidad de adaptación, también habría desarrollado estrategias para beneficiarse en lo posible (o por lo menos no salir demasiado perjudicado) de un esquema caciquil y clientelar dominante a nivel estructural ${ }^{54}$, hipótesis que en su comprobación debería de tener muy en cuenta la existencia de gradaciones internas dentro del colectivo campesino que sin duda influyen tanto en la percepción del fenómeno como en su posible instrumentalización (sería el caso, por ejemplo, del campesino acomodado con posibilidad de dar una educación a sus hijos y aprovechar el entramado clientelar para situarlo en la administración). En todo caso, y se confirmen o no éstas y otras hipótesis, de lo que no cabe duda es de que sólo avanzando en un mejor conocimiento del arraigo social del caciquismo y de sus beneficiarios (principales y secundarios), podremos acercarnos a la comprensión de su extraordinaria longevidad.

53 Garrido Mar'ín, A., "Clientelismo y localismo...», cit., pág. 249 (habla de «burguesocracia»); Hervís SAYAr, H., "O Unicato Bugallalista: Ponteareas, 1891-1923. Elementos para unha análise do caciquismo e do clientelismo politicos na Galicia da Restauracióny, en FERNÁNDEZ PRIETO, L. et al. (coords.), cit., págs. 213, 222-223; SALVNTI, M., «Ceti medi e rappresentanza politica tra storia e sociologias: Rivista de storia contemporanea, 3 (1988) 351-386; RUBINSTEIN, W. D., «The End of «Old Corruption» in Britain, 1780-1860»: Past and Present, 101 (1983) 62. Un acercamiento al escurridizo tema de la pequeña burguesía, en NúNiz SEIXAS, X. M., « Una clase inexistente? La pequeña burguesía española (1808-1936)»: Historia Social, 26 (1996) 19-45. 15.

54 Fernández Prieto, L., et al., «Introducción: poder local...», en Id. (coords.), cit., pág.

Nitpania, LIX/2, núm. 202 (1999) 637-661 